\title{
DA MILITARIZAÇÃO AO ENCARCERAMENTO: UMA VISÃO SOBRE O PROCESSO DE SEGREGAÇÃO URBANA NO MUNICÍPIO DO RIO DE JANEIRO
}

\section{Urban militarization and incarceration: a perspective about the urban segregation process in the municipality of Rio de Janeiro}

\author{
Mariana dos Santos Nesimi \\ Graduada em Geografia pela UFRJ \\ mariananesimi@outlook.com
}

Artigo enviado para publicação em 09/07/2020 e aceito em 11/10/2020

DOI: $10.12957 /$ tamoios.2020.52618

\section{Resumo}

Neste artigo, pretende-se discutir a tese de que determinados locais da cidade, em virtude de um longo processo de marginalização, passam a ser estigmatizados como territórios do crime, lar de potenciais criminosos. Além das políticas de segregação que são promovidas no espaço a partir dessa perspectiva, hoje é possível destacar um aprofundamento desta lógica através do movimento de confinamento espacial, que tem como objetivo "garantir" o ordenamento urbano. Destacam-se como exemplos de confinamento a militarização do espaço urbano e as medidas de encarceramento, que embora sejam movimentos distintos, compartilham alvos e práticas.

Palavras-chave: militarização do espaço urbano; encarceramento; segregação urbana.

\begin{abstract}
In this article, the idea is to discuss the thesis that some places in the city, that go through a long process of marginalization, are now stigmatized as territories of crime, home to potential criminals. Besides the policies of segregation social that are promoted in space from this perspective, today we can observe a deepening of this logic through the movement of spatial confinement, with objective is "guarantee" the order in the city. We use as examples of confinement the militarization of urban space and the incarceration, which although they are distinct movements, share targets and practices.
\end{abstract}

Keywords: urban militarization; incarceration; urban segregation. 


\section{Introdução: quando as favelas se tornam alvos}

A tese central do presente artigo se apoia na visão de que determinados locais da cidade estão marcados como territórios do crime, responsáveis por abrigar uma parcela da população que, a partir de uma construção social, é considerada como perigosa. Acredita-se que por isso, processos de controle e confinamento passam a ser aclamados por partes mais abastadas da população, simbolizando uma forma de "garantir a ordem" na cidade e ampliando os processos de segregação urbana que historicamente estão presentes na cidade do Rio de Janeiro. Este controle vem sendo expresso pela militarização do espaço urbano, cada vez mais presente na paisagem urbana, e pelo encarceramento que atuam de forma integrada e penalizam uma parcela específica da população.

Com o objetivo de embasar as teorias apresentadas, conceitos como militarização do espaço urbano, controle territorial, encarceramento e segregação urbana serão centrais no trabalho. Além disso, a metodologia apreendida consiste na revisão bibliográfica dos referidos temas, na análise de relatórios voltados para o contexto da militarização do espaço urbano no município do Rio de Janeiro e do estudo elaborado pela Fundação Getulio Vargas, em 2015, denominado de Geografia do Encarceramento, que estudou os bairros que mais concentravam declarações de residência de apenados no município do Rio de Janeiro. Para que a relação entre a militarização do espaço urbano e o encarceramento fosse evidenciada, foram utilizados como exemplos neste texto os episódios da Operação São Francisco, realizada no Complexo da Maré, em 2014; e da Intervenção Federal do Rio de Janeiro, decretada em 2018.

Ainda que a população, de uma maneira geral, seja acometida pelos problemas relacionados à violência urbana, a história do Rio de Janeiro demonstra que as favelas são os alvos principais, estando, inclusive, mais suscetíveis às ações violentas cometidas por grupos armados com domínio de território (SILVA et al., 2008) ou até por parte do Estado. Sabendo que as favelas são ocupadas majoritariamente por negros, torna-se possível estabelecer uma relação entre os processos de segregação, violência urbana e a questão racial.

As favelas surgiram a partir da impossibilidade por parte de alguns grupos de garantir moradia. Durante muito tempo, representaram também uma opção de reprodução social, uma vez que permitiam o acesso aos serviços e produtos a preços mais baixos ou, até mesmo, fora do mercado. Dessa forma, as favelas eram frequentemente associadas à informalidade, à pobreza e ao desemprego. Quando as favelas passam a abrigar a parte mais empobrecida da cidade, elas começam a carregar, de forma subsequente, o estigma da criminalização da pobreza.

Assim, elas passaram a ser vistas por parte da sociedade como territórios violentos e perigosos, que estabeleceriam uma relação direta com um processo intenso de desordem urbano-social. Seguindo esta ideia, os moradores desses espaços representavam um mal a ser combatido ou, no mínimo, afastado do campo visual. Na tentativa de evitar que esses grupos ocupassem outras áreas da cidade, as políticas reguladoras passam a ser desejadas e aclamadas por segmentos da imprensa e elite, que os consideravam como indesejáveis. Como demonstra Cecilia Coimbra (2001), as classes perigosas passam por um contínuo processo de abandono e desrespeito. Os moradores das favelas do Rio de Janeiro, na passagem para o século XX, a partir de uma justificativa que era de ordem sanitária, estavam sujeitos às ações repressivas e autoritárias cometidas pelos policiais sanitários. Esses espaços, nesse período, sobretudo os que ficavam em áreas centrais, eram frequentemente associados à insalubridade e à 
reprodução de doenças; e seus moradores, evidentemente, vistos como os vetores e a causa principal delas.

Sabendo que o processo de expansão das favelas está diretamente ligado à ampliação da demanda e a oferta de serviço nas áreas centrais, mais à frente, durante o processo de industrialização do país, iniciado na década de 1930, como consequência dos diversos processos migratórios, ocorreu um crescimento populacional intenso ${ }^{1}$. No caso do Rio de Janeiro, as favelas foram construídas, em sua maioria, em locais pouco requeridos e com baixo valor do solo, passando a representar o espaço de morada dos trabalhadores. Nesse período, uma nova relação entre o Estado e as favelas é estabelecida (BOTELHO; NESIMI, 2019, p.290). Os moradores das favelas, antes entendidos como doentes e criminosos, passam a ser reconhecidos pelo ideal do trabalho durante o período varguista.

Essa compreensão de que uma parte dos moradores das favelas são "gente de bem", "trabalhadora", entretanto, não é alheia à visão preconceituosa genérica daquele espaço como "pestilento" e "criminoso" — daí que o papel do Estado seja exatamente o de remover essas comunidades ou civilizá-las através da urbanização (BOTELHO; NESIMI, 2019, p.291).

Entre os anos de 1945 e 1965, ocorre uma mudança significativa na dinâmica da paisagem: a partir de um processo de valorização imobiliária e aumento do preço do solo, começa uma série de remoções de favelas. Esse movimento de caráter arbitrário foi motivado principalmente pelos interesses da elite que, nesse contexto, passou a reivindicar áreas que até então eram esquecidas. No caso da Zona Sul da cidade do Rio de Janeiro, o espaço passou a evidenciar os contrastes sociais, sinalizando uma ocupação hierárquica e desigual do solo.

Isto posto, percebe-se que enquanto as favelas desempenhavam o papel de circuito inferior da economia, fornecendo serviços e produtos a baixo custo para as camadas médias da sociedade, pertencentes ao circuito superior (SANTOS, 1978), elas eram suportadas. A partir do aumento do preço do solo, em virtude de um conflito de interesses, elas perdem sua funcionalidade e não se fazem mais necessárias para a manutenção social. Assim, cria-se uma política de remoções que prevê o afastamento geográfico desses grupos das áreas centrais da cidade.

Muitas remoções foram postergadas ou até impedidas devido aos oportunos defensores dos direitos dos moradores das favelas: como era uma população em ascensão numérica, eles passaram a ser vistos enquanto potenciais eleitores. Defender determinadas pautas dos moradores, portanto, tornou-se uma estratégia política. Mesmo com estas interferências convenientes, algumas favelas vivenciaram o processo de remoção e muitos moradores foram obrigados, de forma repentina, a deixarem suas casas - muitos para áreas distantes das que estavam acostumados a viver. Durante o período da ditadura militar, houve um agravamento no processo de remoções, o que representou um aumento da repressão aos mais pobres e substancialmente da população negra.

É a "política urbana do abandono concentrado" que passa a vigorar em nossos dias: radicalização das reordenações urbanas da primeira metade do século passado - mediante as quais os miseráveis são empurrados para os "bolsões de pobreza", para os guetos; completa estigmatização dos "territórios dos pobres" os quais, mais do que 
nunca, são vistos como perigosos, portanto, totalmente abandonados pelas políticas públicas. (COIMBRA, 2001, p.251).

Nos anos seguintes, ocorreu uma mudança na forma de perceber as favelas no espaço urbano. O governo de Leonel Brizola, em seu primeiro mandato como governador do Rio de Janeiro, vai adotar uma política integracionista: as favelas deveriam passar a fazer parte da cidade em um sentido mais amplo, e não apenas existir na paisagem. Logo, criam-se projetos que visavam melhorar a infraestrutura da favela, até então muito precária, e ocorreu um movimento que buscava superar a ideia de ilegalidade, frequentemente associada a esses espaços. No entanto, esta virada política teve um alcance limitado.

A política de remoções continuou em segundo plano nos anos que sucederam. $\mathrm{O}$ período que compreende as décadas de 1990 e início dos anos 2000 foi marcado por discursos que davam continuidade, pelo menos formalmente, a uma política de integração entre a favela e as demais áreas da cidade, através de um processo de urbanização. A partir desta nova política de governo, surgem programas como o FavelaBairro, Bairrinho e Grandes Favelas, que tinham como objetivo democratizar o acesso aos serviços essenciais.

Apesar da implementação desses projetos, eles não conseguiram dar fim às disparidades sociais existentes no espaço e nem romper com o estigma da criminalização. Com um aumento nas taxas de criminalidade na década de 1990, vinculado ao tráfico de drogas, a violência urbana passou a ser ainda mais associada às favelas: seus limites geográficos e áreas adjacentes, que eram consideradas extensões das favelas mesmo no asfalto, eram vistos como territórios perigosos.

A partir da eleição de Eduardo Paes para a prefeitura do Rio de Janeiro (20092016), o período de remoções volta a ser uma realidade no município. Em 2010, ocorre a criação de o projeto Morar Carioca, que tinha como proposta urbanizar $100 \%$ das favelas até o ano de 2020, criando conjuntos habitacionais e promovendo uma integração (CARVALHO, 2016, p.51), o que não foi cumprido. Percebe-se, contudo, que esse projeto de urbanização estava vinculado a ocorrência dos Megaeventos no Rio de Janeiro e que também estava diretamente ligado a um projeto de segurança que seria implementado. Ainda, como afirma Mario Brum (2013, p.191), o status imutável da favela como um espaço criminalizado fazia com que a discussão sobre as remoções sempre voltasse a ser considerada.

Com essa introdução, a proposta é apresentar uma síntese do contexto histórico que situou a favela na sociedade como sendo um espaço criminalizado. Atualmente, com a ampliação do entendimento sobre o que são as guerras, leva-se a pensar, sobretudo pelo papel desempenhado pelas mídias, que existe uma espécie de guerra urbana, onde as favelas são vistas cada vez mais como espaços de conflitos. Como sinaliza Cecília Coimbra (2003, p.4), a partir da ideia de existir uma "guerra civil", ocorre a afirmação e até o fortalecimento de um modelo de segurança pública que historicamente se faz presente nos territórios de pobreza, militarizando em razão de uma busca por "segurança".

Dessa forma, torna-se possível pensar em um novo modelo de segregação urbana em curso nas cidades, onde isolar a parte mais pobre da população passa a não ser mais o suficiente. Para além deste movimento, é preciso regular e controlar seus cotidianos por meio de práticas ostensivas e repressivas, como através do encarceramento dos indesejáveis ou do processo de militarização do espaço urbano que, embora sejam movimentos diversos, atuam de forma conjunta. 


\section{A manifestação espacial do encarceramento: o estudo da Fundação Getulio Vargas}

O encarceramento sempre desempenhou um papel de controle na sociedade, contribuindo sistematicamente para a perpetuação de uma ideia de afastamento de determinados grupos da sociedade como forma de resolução dos problemas sociais (ALEXANDER, 2008). No entanto, torna-se uma instituição que reproduz desigualdades, tendo um forte cunho racista presente em suas dinâmicas. Esse elemento do encarceramento fica expresso nos relatórios ligados ao tema: dados extraídos a partir do Departamento Penitenciário Nacional, em 2017, apontavam que a maioria dos apenados tanto no Brasil quanto no Rio de Janeiro eram negros ${ }^{2}$.

Uma pesquisa elaborada pela Fundação Getulio Vargas (FGV), em 2015, nomeada de Geografia do Encarceramento, tinha como proposta central entender a origem geográfica dos apenados - e dos crimes mais recorrentes que levavam ao aprisionamento - no município do Rio de Janeiro. A partir da análise de 18.438 fichas, disponibilizadas pela Secretaria do Estado de Administração Penitenciária (SEAP), referentes aos presos que estiveram em situação de cárcere entre os meses de janeiro a julho do referido ano, o estudo conseguiu fazer algumas constatações.

A primeira observação feita refere-se ao fato de que existe uma concentração de declarações de residência dos apenados em alguns bairros. Dentre eles, em números absolutos, Bangu possuía o maior índice: 875; enquanto o segundo lugar, Bonsucesso, possuía 603. Em relação a esses dados, é importante sinalizar que, segundo o estudo, no caso de Bangu, há um destaque de declarações para as áreas da Vila Kennedy e Vila Aliança e, no caso de Bonsucesso, há a particularidade dessas declarações envolverem a Maré, sendo o destaque observado para o Parque União e Nova Holanda.

Os dados populacionais dos bairros também são apresentados no estudo. Bangu possuía, na época, o equivalente a 243.125 habitantes; ao passo que Bonsucesso possuía 18.711 habitantes. Cruzando esses dados com os do encarceramento, a discrepância dos números populacionais chama atenção, principalmente se pensarmos que, apesar de Bangu concentrar a maior declaração de residência em números absolutos, o bairro de Bonsucesso, se considerado a taxa de detentos por habitantes, passa a representar o primeiro bairro com mais declarações de residência de apenados. Quando os dados populacionais relacionados à Maré são observados, a discrepância é minimizada: o bairro tinha um total de 129.770 habitantes. Ainda assim, mesmo que somadas as populações de Bonsucesso e Maré, o número seria inferior à população total de Bangu.

A partir do estudo apresentado, destaca-se o elemento racial contido nesses processos: no ano de 2015, o Rio de Janeiro tinha uma população dividida entre $51 \%$ branca, $36 \%$ parda e $11 \%$ preta. Observando os dados que correspondem aos bairros que concentram as declarações de residência dos apenados, trata-se de bairros ocupados majoritariamente pela população negra - Bangu e Maré possuíam, na época, o equivalente a $60 \%$. Tal fato também fica expresso no sistema carcerário: segundo o estudo da FGV, ele era dividido em uma população de $45 \%$ pardos, $25 \%$ negros e $26 \%$ brancos (FGV, 2015). Embora brancos fossem a maioria no município do Rio de Janeiro, a população negra era a mais punida.

Esses dados evidenciam as contradições de um espaço marcado pelas questões raciais e sociais: apesar de Bangu, Bonsucesso e Maré concentrarem a maior quantidade de declarações de apenados no município do Rio de Janeiro, os bairros com maior quantidade de crimes praticados que levaram à detenção, em números absolutos, são Grajaú e Centro - Bangu aparece na terceira posição. Este mesmo índice, visto pelo critério de mil habitantes, coloca como os principais bairros a Cidade Nova e Grajaú Bonsucesso aparece em terceiro. 
Estas questões levantam algumas hipóteses: a primeira refere-se ao fato de que o maior número de crimes se dá em áreas centrais do município do Rio de Janeiro, locais onde temos um fluxo maior e mais intenso de pessoas e capital. E isso poderia corroborar com as ações policiais mais efetivas de garantia da ordem, em uma espécie de "patrulhamento", e justificar uma maior taxa de aprisionamento nessas áreas, uma vez que, visando garantir a segurança e a tranquilidade de transeuntes, seria preciso afastar e retirar pessoas indesejáveis de circulação. Outra questão é que a análise desses dados, por si só, já desmonta a ideia comum de que determinadas áreas como a Zona Oeste do Rio de Janeiro e demais áreas favelizadas da cidade são mais violentas e representariam uma ameaça à vida na urbe. A partir desta justificativa, seria respaldada a ideia de que controlar e promover um confinamento dos moradores dessas áreas se tornariam formas de evitar um possível alastramento dos riscos para as áreas centrais.

\section{A militarização como uma forma de controle}

Historicamente, ações militares são requeridas com o intuito de atuar frente à garantia do território na cidade. Quanto a isso, o geógrafo Marcelo Lopes de Souza, em alguns estudos, indicou uma "militarização do quotidiano" ou uma "militarização da questão urbana" em curso (SOUZA, 2008). Este projeto, pautado no controle ostensivo, seria uma consequência - ou uma resposta direta - ao clima de insegurança diariamente sentido em Fobópoles ${ }^{3}$ (2008) como o Rio de Janeiro.

Assim como demonstram Barreira e Botelho, quanto maior for a sensação de insegurança, maior será a chance de o aparelho estatal impor seu controle sem contestação (2013, p.126). Desta maneira, abre-se uma brecha para justificar o controle exercido em territórios de pobreza que sempre foram vistos enquanto locais ameaçadores e com alto grau de periculosidade, tornando-se consequentemente uma forma de legitimar ações oficiais violentas. É interessante ressaltar que este controle ocorre de forma distinta e hierarquizada: assim como no sistema carcerário, estas políticas são destinadas a uma parcela específica da população, mesmo que acabem impactando nas demais áreas. As ações do Estado, por vezes arbitrárias, são defendidas por parte da sociedade, porque elas podem representar a manutenção de determinados interesses, ou porque elas podem ser encaradas como uma das mais justas diante das que estão postas para atuar na regulação das relações sociais.

Nesse contexto, surgem as Operações de Garantia da Lei e da Ordem (GLO), previstas na Lei Complementar no 97/1999. Sua definição está prevista e assegurada em situações em que há o esgotamento das forças tradicionais de segurança pública, em graves situações de perturbação da ordem. Por consequência, concedem de forma provisória que os militares atuem com poder de polícia, de forma permanente ou esporádica, em áreas antes estabelecidas, até o restabelecimento das condições consideradas normais (RODRIGUES; ARMSTRONG, 2019, p.11).

Segundo o Ministério da Defesa, entre os anos de 1992 e 2017, ocorreram 132 operações de Garantia de Lei e da Ordem no Brasil. Estas ações apresentaram uma duração que oscilava entre um e três meses, representando missões curtas (MD, 2017 apud RODRIGUES; ARMSTRONG, 2019, p.12). Apenas seis, do quantitativo geral, apresentaram prazos de duração maiores ou equivalentes há cinco meses. Das 132 operações GLO, vinte ocorreram no Rio de Janeiro; a grande maioria, inclusive no município, estava relacionada à segurança pública ou à violência urbana.

Dentre muitos casos que poderiam representar o intenso processo de militarização aplicado na cidade, destacam-se dois: o do complexo da Maré e o da Vila Kennedy que não coincidentemente são áreas indicadas pela pesquisa da FGV como 
sendo os bairros que concentram as maiores declarações de apenados no município do Rio de Janeiro. Ainda que essas operações tenham ocorrido em situações e anos distintos, podemos perceber algumas semelhanças.

O Complexo da Maré, localizado na Zona Norte do Rio de Janeiro, é considerado um dos maiores conjuntos de favelas do Estado ${ }^{4}$. A partir de uma GLO, entre o período de 5 de abril de 2014 e 30 de junho de 2015, com a ocupação dos fuzileiros navais na região ${ }^{5}$, deu-se início a Operação São Francisco, que garantiu aos militares o direito de exercer funções policiais em um raio de $10 \mathrm{~km}^{2}$. Assim eles tinham autonomia para realizar procedimentos de rotina, como patrulhamentos e revistas, ou até realizar prisões em flagrante (SILVA, 2017, p.14).

Estas ações, teoricamente, visavam contribuir para uma pacificação do território e fornecer as condições necessárias para a implementação de uma Unidade de Polícia Pacificadora (UPP) na região ${ }^{6}$. Um dos impactos diretos desse processo se deu a partir da migração de determinados grupos armados, pertencentes a favelas adjacentes, como Manguinhos e Jacarezinho, para a Maré, o que acabou promovendo mudanças nas estruturas relacionadas à divisão do poder e do território no Complexo, gerando uma maior preocupação do governo em controlar e assumir estes espaços (SILVA, 2017, p.17).

Preocupação essa que foi intensificada graças à ocorrência dos megaeventos no país: controlar estes espaços seria uma forma de tranquilizar a população, pois significaria que os males, que normalmente acometem à cidade, estariam controlados. No entanto, de acordo com o levantamento apresentado no relatório A Ocupação da Maré pelo Exército Brasileiro - percepção de moradores sobre a ocupação das forças armadas na Maré (2017), esta sensação de tranquilidade não necessariamente chegaria até os principais envolvidos na intervenção: os moradores do Complexo. Dados demonstram que, apesar de uma parte significativa da população residente do Complexo declarar apoio ao modelo, quando questionados sobre possíveis mudanças no sentimento de segurança a partir da entrada da "força de pacificação" na Maré, $46.8 \%$ dos moradores disseram que não houve mudança nenhuma $\left(2017\right.$, p.68) ${ }^{7}$.

Outras questões chamam atenção no contexto da ocupação do Complexo. Desde o início da atuação do exército na região, 140 pessoas foram denunciadas e investigadas na Justiça Militar. As principais ocorrências são o desacato, desobediência e resistência, previstas no Código Penal Militar ${ }^{8}$. As ocorrências citadas revelam duas situações no mínimo contraditórias: os crimes reportados, que culminaram no cárcere de alguns, eram crimes de hierarquia, não estando necessariamente associados ao uso da violência. Outro fator de distinção neste caso é que civis foram julgados em instituições militares, tendo como principal instrumento de acusação a palavra ou o relato dos militares envolvidos no processo, o que pode evidentemente manifestar arbitrariedades.

E este é um ciclo de violência que parece não ter fim: em agosto de 2019, a ONG Redes da Maré entregou para a Justiça uma petição na tentativa de regular às operações policiais que ocorriam com uma frequência no local. Junto à petição, foram anexados 1500 desenhos e cartas de crianças que moravam no Complexo, onde expressavam seus medos rotineiros em relação aos conflitos que eram estabelecidos no local $^{9}$.

A partir de um decreto expedido, no dia 16 de fevereiro de 2018, que declarava a Intervenção federal no Rio de Janeiro, começa um processo de militarização mais aparente na Vila Kennedy. Essa intervenção, que inicialmente tinha o encerramento de suas atividades previsto para o dia 31 de dezembro de 2018, possuía como objetivo principal pôr termo o grave comprometimento da ordem pública no Estado do Rio de Janeiro (Decreto no 9288/18). O militar Walter Braga Netto foi o escolhido para 
assumir o cargo de interventor, passando a ocupar, no que tange à segurança pública, o papel do governador do estado (RODRIGUES; ARMSTRONG, 2019, p.6).

Não obstante, a intervenção federal restringiu-se a segurança pública. A partir de fevereiro de 2018, as forças armadas passaram a comandar e administrar diretamente todo o aparato policial, prisional e o corpo de bombeiros do estado, e foram iniciadas negociações para a transferência de recursos federais para a segurança pública no Rio de Janeiro. (RODRIGUES; ARMSTRONG, 2019, p.9).

As primeiras operações realizadas que envolviam diretamente a utilização das forças armadas, durante a intervenção federal no Rio de Janeiro, foram o patrulhamento de rodovias, uma incursão realizada a um presídio e a ocupação pelos militares de algumas favelas da Zona Oeste do Rio de Janeiro: Vila Kennedy, Vila Aliança e Coreia. Todas as três favelas estabelecem relação com o bairro de Bangu: a Vila Kennedy, antes de se tornar um bairro, era uma subdivisão de Bangu; a Vila Aliança faz parte oficialmente de Bangu e a favela da Coreia pertence ao bairro de Senador Camará, que faz limite com Bangu e muitas vezes tem seus limites confundidos.

Diferente do caso do Complexo da Maré, no caso da intervenção federal nessas favelas, os militares tinham horários preestabelecidos para chegar e deixar o local, o que, ainda assim, não impediu a ocorrência de relatos que apontavam abusos de poder. De acordo com o relatório A Intervenção Federal no Rio de Janeiro e as Organizações da Sociedade Civil (2019), as primeiras denúncias realizadas dos excessos cometidos pelos militares estão relacionadas a um movimento de "cadastramento" dos moradores. Segundo uma reportagem realizada pela Folha de São Paulo, em 2018, os moradores só teriam permissão para deixar a favela caso passassem por algum dos muitos pontos de cadastramento criados em diferentes saídas das favelas (RODRIGUES; ARMSTRONG, 2019, p.21).

As fotos dos moradores e de seus registros de identificação eram encaminhadas para o setor responsável pela parte de inteligência da intervenção, onde era checado se os moradores tinham ficha criminal (RANGEL; VERPA, 2018 apud RODRIGUES; ARMSTRONG, 2019, p.21). Logo, percebe-se que a ideia que coloca os moradores das favelas como suspeitos e potenciais criminosos continua em vigor, definindo ações de controle e reproduzindo uma lógica de segregação na cidade.

A Ordem dos Advogados do Brasil no Rio de Janeiro (OAB/RJ), junto a Defensoria Pública e algumas ONGS que trabalham para a garantia dos direitos humanos, repudiaram tal fato e cobraram explicações ${ }^{10}$. No dia 23 de fevereiro, a Defensoria Pública da União encaminhou um conjunto de recomendações ao interventor Walter Braga Netto, que solicitava a garantia dos direitos básicos e preservação da dignidade da população humana; a não imposição de barreiras que pudessem impedir a circulação dos moradores e ao não prosseguimento das ações de fotografar e fichar os moradores (DPU, 2018 apud RODRIGUES; ARMSTRONG, 2019, p.21).

O dia 14 de março de 2018 é marcado pelas mortes da vereadora Marielle Franco e Anderson Gomes, perseguidos e mortos no bairro do Estácio. Este episódio, que deu início a infinitos protestos que se estendem até hoje, gerou um desgaste no modelo de segurança pública que vigorava, ocorrendo uma desaceleração das ações GLO em espaços populares. Por conseguinte, a ocupação na favela da Vila Kennedy e adjacências passou por um processo de desmobilização e as demais ações relacionadas a 
GLO, como consequência, foram finalizadas em abril (RODRIGUES; ARMSTRONG, 2019, p.23).

Durante o período da intervenção federal, ocorreram 49 operações GLO, sendo 44 dessas ações em áreas favelizadas ou bairros populares da capital e outros municípios (RODRIGUES; ARMSTRONG, 2019, p.31). Em um primeiro momento, as operações se concentravam na Zona Oeste da cidade e ocorriam, de forma esporádica, em outras áreas. Em seguida, a Zona Norte da cidade passa a sofrer operações, principalmente nos bairros que faziam divisa com a Baixada Fluminense. Em agosto, ocorrem grandes operações em alguns complexos pertencentes à Zona Norte da cidade, como o Complexo da Penha, Alemão e Maré.

Contudo, é possível reafirmar que essas ações são igualmente espacializadas: elas existem e são requeridas em locais específicos. O Complexo da Maré, durante a intervenção federal, voltou a ser alvo de questionamentos, uma vez que, a partir das operações realizadas nas favelas, durante este período, muitos acreditavam que uma nova intervenção fixa no território seria implementada.

Apresentando um balanço das operações realizadas durante a Intervenção Federal, são sinalizadas algumas práticas excessivas cometidas por militares em serviço: o fichamento e as fotos tiradas tanto dos moradores quanto de suas identidades; a verificação de possíveis fichas criminais dos moradores a partir de uma "central"; a revista dos automóveis que acessavam os limites das favelas, independente de quem fosse; o cumprimento de mandados de prisão e, por último, a ocorrência de inúmeros tiroteios na região (RODRIGUES; ARMSTRONG, 2019, p.32). Quanto a isso, ressaltase que, segundo o relatório Intervenção Federal: um modelo para não copiar (2019), elaborado pelo Observatório da Intervenção, a Vila Kennedy, chamada de "laboratório da intervenção", registrou um aumento de 17\% no número de homicídios dolosos e registrou um aumento equivalente a $174 \%$ no registro de trocas de tiros ou disparos realizados na região durante o período. De acordo com Viana (2018 apud RODRIGUES; ARMSTRONG, 2019, p.13), as operações GLO têm causado mortes violentas de civis por militares e, em menor proporção, morte de militares.

\section{Conclusão}

Através do estudo de dois bairros, Maré e Bangu, apontados a partir da pesquisa da Fundação Getulio Vargas (FGV) como sendo os bairros que mais concentram declarações de residência dos apenados no município do Rio de Janeiro, objetivou-se estabelecer uma relação entre dois padrões de controle existentes: a militarização do espaço urbano e o encarceramento. Ambos os bairros, situados em áreas periféricas e favelizadas do município do Rio de Janeiro, passam por processos históricos de marginalização que reforçam estigmas e corroboram para a efetivação de práticas de controle.

Estigma que é baseado na ideia de que o perigo e a violência estariam concentrados em determinadas áreas de pobreza na cidade, como demonstramos na primeira seção. Em virtude disso, seria preciso pensar em formas de controle que fossem além de um mero e habitual afastamento geográfico de determinados grupos. Dessa forma, adota-se, como medida estatal, o controle de alguns territórios e o encarceramento das classes entendidas como perigosas.

Como demonstrado ao longo do artigo, a partir da análise dos processos de militarização do espaço urbano na cidade do Rio de Janeiro, por meio dos relatórios vinculados ao Instituto de Pesquisa Econômica Aplicada (IPEA) e Redes Maré, alguns exemplos podem indicar o controle territorial adquirindo feições mais efetivas e 
precisas: seja na apreensão de pessoas que foram julgadas por crimes de desacato e desobediência durante a ocupação das Forças Armadas no Complexo da Maré, ou no caso do fichamento e cadastramento dos moradores na Vila Kennedy, no período da Intervenção Federal no Rio de Janeiro, as dinâmicas da cidade passam por mudanças e apresentam uma nova configuração. De acordo com Coimbra, a construção da ideia de existir uma "guerra civil" é utilizada historicamente como instrumento para legitimar violações e domínios de certos grupos sobre outros, justificando a aplicação de "medidas de exceção" (2008, p.1).

Acredita-se que os movimentos de militarização do espaço urbano e encarceramento se tornam convergentes e até contínuos à medida que compartilham os mesmos alvos, práticas e até objetivos. Para além da segregação convencional, realizada através do afastamento de determinados grupos, esses processos, em situações extremas, acabam sendo a consequência do processo de segregação manifestada no território, favorecendo um confinamento urbano e um apagamento das vivências daqueles que são indesejados e, consequentemente, mais penalizados.

Embora existam relatórios que forneçam dados acerca dos processos, realizados por diferentes Institutos de Pesquisa, há uma dificuldade de ter acesso completo e transparente de alguns dados, sobretudo os mais recentes, o que pode contribuir, em termos, para uma investigação limitada. A presente pesquisa, inclusive, foi marcada por entraves durante sua elaboração ao tentar ter acesso a dados mais atualizados, requeridos à Secretaria de Estado de Administração Penitenciária (SEAP), no ano de 2019, com o objetivo de atualizar o estudo elaborado pela Fundação Getulio Vargas e realizar investigações mais amplas em relação às políticas de controle em andamento na cidade. No entanto, sendo o Rio de Janeiro laboratório e palco de medidas de segregação e punição, é de extrema importância que se produzam trabalhos que busquem discutir essa questão. Portanto, longe de apresentar ideias conclusivas e fechadas, pretende-se contribuir com a análise de um processo em curso que, diariamente, apresenta especificidades.

\section{Notas}

1 - O aumento das cidades e consequentemente da população não seguiu a mesma proporção da oferta de empregos, assim como as favelas se tornaram o local de morada dos trabalhadores ligados a indústria, também foram lar daqueles que eram rejeitados da sociedade de mercado.

2 - Segundo o relatório, a população brasileira era dividida em $46.8 \%$ de pardos, $8.6 \%$ de pretos e $43.6 \%$ de brancos. No sistema penitenciário, a distribuição da racial da população ficava em: $46.27 \%$ de pardos, $17.37 \%$ de pretos, $35.48 \%$ de brancos e, praticamente, $1 \%$, correspondia aos amarelos e indígenas. No caso do Rio de Janeiro, a distribuição da população carcerária ficava em: $46.24 \%$ de pardos, $27.02 \%$ de pretos, $25.49 \%$ de brancos, $1 \%$ equivalia ao somatório de amarelos e indígenas e $1.18 \%$ não informou.

3 - O termo trata-se da combinação das palavras gregas "phóbos", que significa "medo", e "pólis", que significa "cidade".

4 - O Complexo da Maré, que possui 16 favelas, teve 15 delas ocupadas. A exceção foi a favela Marcílio Dias que, quando a Maré foi reconhecida e delimitada enquanto bairro, a partir de uma lei de 1994, não foi incluída no limite geográfico. Oficialmente ela pertence ao bairro Penha Circular.

5 - Além dos fuzileiros da Marinha, a operação também contou com apoio logístico da aeronáutica.

6 - O Complexo da Maré possui uma fragmentação territorial presente no Complexo que corroborou para o acontecimento de muitos conflitos, principalmente antes da ocupação. Dentre os grupos armados com domínio de território presentes no Complexo, podemos citar: o Comando Vermelho (CV), Amigos dos Amigos (ADA), Terceiro Comando Puro (TCP) e as Milícias.

7 - Os outros dados são: $8.4 \%$ disseram que melhorou muito; $22.5 \%$ que melhorou pouco; $7.7 \%$ que piorou pouco e $14.7 \%$ responderam que piorou muito.

8 - Disponível em: https://exame.abril.com.br/brasil/justica-militar-investiga-civis-por-desacato-maspoupa-soldados-que-matam/ Acesso em: abr, 2020. 
9 - Disponível em: https://extra.globo.com/casos-de-policia/criancas-da-mare-entregam-cartas-desenhosao-tribunal-de-justica-do-rio-pedindo-menos-violencia-na-comunidade-23874257.html Acesso em: abr, 2020.

10 - Disponível em: https://veja.abril.com.br/brasil/defensoria-e-oab-condenam-fichamento-demoradoresno-rj/ Acesso em: abr, 2020.

\section{Referências Bibliográficas}

ALEXANDER, Michelle. A nova segregação: racismo e encarceramento em massa. 1.ed. - São Paulo: Boitempo, 2018. 374 p.

BARREIRA, Marcos e BOTELHO, Maurilio. O exército nas ruas: da operação Rio à ocupação do Complexo do Alemão. Notas para uma reconstituição da exceção urbana. In: BRITO, Felipe e OLIVEIRA, Pedro Rocha de. Até o último homem: visões cariocas da administração armada da vida social. São Paulo: Boitempo, 2013. P.115 -128.

BRUM, Mario Sérgio Inácio. Favelas e remocionismo ontem e hoje: da ditadura de 1964 aos Grandes Eventos. O Social em questão. ANO XVI, n²9, p. 179- 208, 2013.

NESIMI, Mariana dos Santos; BOTELHO, Maurilio Lima. Das favelas às prisões: transformações na segregação urbana no Rio de Janeiro. Revista Continentes, [S.1.], n. 16, p. 285-315, jun. 2020.

CARVALHO, Camila Lima e Silva de. "Cidades" dentro da Cidade? A Estrutura Socioespacial de Favelas Cariocas no Período Lula (2003-2010) / Camila Lima e Silva de Carvalho. -- Rio de Janeiro, 2016. $146 \mathrm{f}$.

COIMBRA, Cecília. Operação Rio: o mito das classes perigosas; um estudo sobre a violência urbana, a mídia impressa e os discursos de segurança pública. Oficina do Autor; Niterói: Intertexto, 2001.

Produzindo o Mito da "Guerra Civil": Naturalizando a Violência. In: BAPTISTA, M.; CRUZ, M.S \& MATIAS, R. (Orgs.). Drogas e Pós-Modernidade 2: faces de um tema proscrito. Rio de Janeiro: Editora da Uerj, 2003.

NESIMI, Mariana dos Santos. Encarceramento e confinamento espacial: uma interpretação sobre o padrão de segregação urbana no município do Rio de Janeiro. Trabalho de Conclusão de Curso (Licenciatura em Geografia) - Universidade Federal Rural do Rio de Janeiro, Seropédica, 2019.

FUNDAÇÃO GETULIO VARGAS (FGV/DAPP). Geografia do Encarceramento. Rio de Janeiro, 2015. Disponível em: http://dapp.fgv.br/geografia-do-encarceramento/. Acesso em: abr, 2020.

RAMOS, Silvia (coord.). Intervenção federal: um modelo para não copiar. Rio de Janeiro: CESeC, fevereiro de 2019.

RODRIGUES, Rute Imanishi e ARMSTRONG, Karolina. A intervenção federal no Rio de Janeiro e as organizações da sociedade civil. IPEA - Instituto de Pesquisa e Econômica Aplicada. Rio de Janeiro, 2019.

SANTOS, Milton. O espaço dividido: Os dois circuitos da economia urbana dos países subdesenvolvidos. Rio de Janeiro: Francisco Alves, 1979 (Coleção Ciências Sociais).

SILVA, Eliana Sousa. A ocupação da Maré pelo exército brasileiro: a percepção se moradores sobre a ocupação das forças armadas na Maré. Rio de Janeiro: Redes da Maré, 2017.

BRAGA, Raquel Willadino, FERNANDES, Fernando Lannes e SILVA, Jaílson de Souza. Grupos Criminosos Armados com Domínio de Território. In: Justiça Global. Segurança, Tráfico e Milícias no Rio de Janeiro. Rio de Janeiro: Fundação Heinrich Böell, 2008. P. 16 - 24.

SOUZA, Marcelo Lopes. Fobópole: o medo generalizado e a militarização da questão urbana Rio de Janeiro: Bertrand Brasil, 2008. 288 p.

Militarização da questão urbana - Lutas Sociais, São Paulo, n²9, 2012. 